\title{
BONE GROWTH IN DIAPHYSIAL ACLASIS
}

\author{
L. Solomon, London, ENGLAND \\ From the Royal National Orthopaedic Hospital, London, and \\ the Hospital for Sick Children, Great Ormond Street, London
}

An example of cartilaginous exostoses-believed by some to be the first described in detail in the literature - was reported in the Guy's Hospital Reports of the Lancet of July 23, 1825. However, it is certain that the condition was known at least half a century before that. In the series of Lectures on the Principles of Surgery which John Hunter delivered in 1786 and 1787 he described the condition of exostosis and distinguished between those that affect one bone and those that affect " almost every bone in the body." The bone ends might be enlarged " as in rickets," which observation led him to suppose that the two conditions were closely related.

There are more numerous references to the condition in the literature of the late nineteenth century, among which the classic papers of Virchow (1876) and Bessel-Hagen (1891) are remarkably detailed and accurate. In all these descriptions, as in those of recent times, interest centred mainly on the multiple cartilage-capped exostoses which are so striking and curious a feature of the disease.

However, an equally important and perhaps a more fundamental aspect of this malady is the widespread effect on the growth of the appendicular skeleton. It was this, above all, that impressed Keith (1920) when he first encountered the condition and led him to adopt the name "diaphysial aclasis," suggested to him by Morley Roberts and still commonly used in this country. He urged that the condition of multiple exostoses be removed altogether from the category of " tumours" and placed among the " disorders of growth." In spite of this, bone growth in diaphysial aclasis has received scant attention. The present investigation forms part of a detailed study of hereditary multiple exostoses carried out at the Royal National Orthopaedic Hospital and the Hospital for Sick Children, Great Ormond Street. The findings are presented in the hope that they will stimulate further study on what is probably the basic defect in this puzzling disease.

\section{MATERIAL AND METHODS}

Eighty-nine cases of diaphysial aclasis have been studied, and of these seventy-six were fully examined by the author. The examination included a full radiographic survey of the skeleton and detailed measurements of height, weight, span, symphysial height and measurement of individual long bones. The skeletal age of every patient under eighteen was estimated against the standards of Greulich and Pyle (1959). When previous radiographs of the hand and wrist were available the skeletal age was estimated from these also, and correlated with the chronological age at that time. There are other methods of estimating skeletal maturityall based on the characteristic appearances of the epiphysial ossification centres at different ages - but the method of Greulich and Pyle offers considerable advantages in a study of a generalised bone disease such as diaphysial aclasis. The reference standards consist of a large series of radiographs of the hand and wrist taken at different ages, showing not only the evolution of ossification centres in the carpal bones but also the slowly changing pattern of the individual bones of the hand as well as the distal ends of the radius and ulna. In this way one can compare skeletal maturation in the tubular bones of the hand, the radius and the ulna (all sites frequently affected by diaphysial aclasis), with the carpal bones, which are very rarely affected by exostoses. 
In plotting the height distribution of these patients standard graphs have been constructed using Tanner's (1958) data for normals up to the age of eighteen, and Kemsley's (1950) figures for normal adults. The problems involved in obtaining normal standards have been discussed at length by Tanner (1958) and will not be repeated here. Although Tanner's and Kemsley's figures for normal adolescents do not coincide, it was decided to show these measurements as a single broken graph rather than as two separate graphs.

Much more difficult to obtain were normal figures for span, symphysial height (" lower measurement ") and symphysis-to-vertex (" upper measurement "). Yet it is important to present these figures-and particularly the comparative upper and lower measurementsbecause they are an indication of the extent to which limb length is affected by comparison with the trunk. The most reliable standards (though unfortunately presented only as mean values) were those of Engelbach (1932), and they are the ones used in this paper.

Finally, in order to minimise the possible errors due to using standards which differ from each other as to population measured and the time of these measurements, a comparable series of "healthy" out-patients attending the Royal National Orthopaedic Hospital were measured as well and checked against the standards used.

The findings are discussed under three main headings: 1) Abnormal bone growth: retardation of bone growth; and adaptations of bone growth due to pressure by adjacent exostoses. 2) Migrating exostoses. 3) Disappearing exostoses.

\section{ABNORMAL BONE GROWTH}

The patient shown in Figure 1 presented simultaneously all the deformities encountered in diaphysial aclasis. Though by no means a dwarf he had the characteristically short stature, being 157 centimetres in height. The left forearm, in addition to being short, showed bowing of the radius, ulnar deviation of the wrist due to a short ulna, and dislocation of the radio-humeral joint. The left hand was broad and stubby, the fingers shorter than those of the right hand. There was genu valgum on the right side and a valgus deformity of the right ankle. There was a mild though definite thoracic scoliosis with vertebral rotation. On radiographic examination the pelvis was distorted and there was bilateral coxa valga. All these deformities, either singly or in varying combinations, have been described before, but there were two further deformities that do not appear in the literature on the subject. Firstly, the left clavicle was clearly diminished in length compared with the right side and on measurement was almost two centimetres shorter than the right. This gave rise to the asymmetrical appearance of the pectoral girdle. Secondly, the thoracic cage under the right scapula presented a gentle indentation where it had moulded itself to a large exostosis on the deep aspect of the scapula (Fig. 2).

Incidence and distribution of deformities-Bony

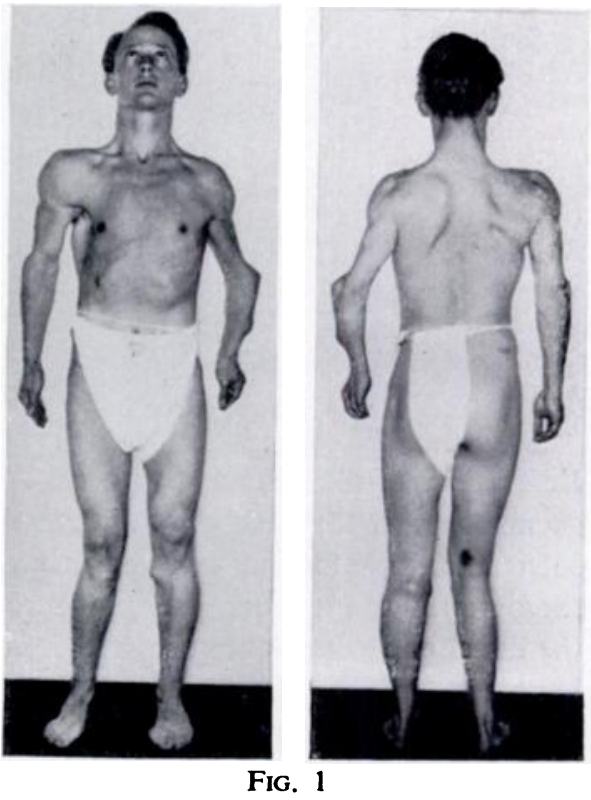

The deformities associated with diaphysial aclasis.

deformities of one sort or another (as distinct from exostoses) were encountered in fifty-six of the seventy-six patients examined in detail, and were distributed equally as to sex (Table I). These fifty-six patients were analysed in greater detail and the occurrence of individual deformities is shown in Table II. No attempt has been made to present figures for conditions like shortening of the clavicles and coxa valga which are in most cases difficult to assess.

VOL. 43 B, NO. 4, NOVEMBER 1961 
Of all these characteristic deformities only the valgus ankles have any clear tendency to be symmetrical. The others are scattered haphazardly in one limb or another, though there is some relationship to the number and size of the exostoses affecting the particular region. When a bone is free from any exostosis an associated deformity is rare.

\section{RETARDATION OF BONE GROWTH}

All the deformities of the tubular bones can be explained in terms of the same common factor: diminished length of the bones affected by the disease. A closer look at the individual deformities will illustrate this point.

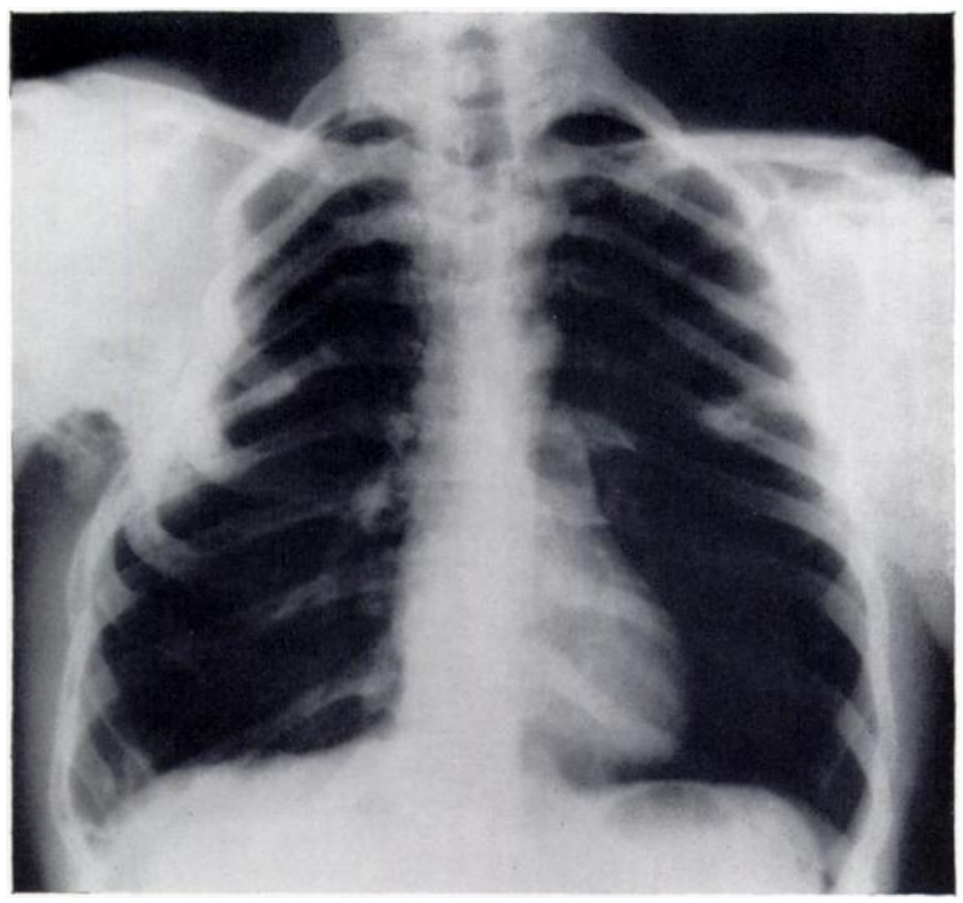

Fig. 2

Radiograph showing deformity of thoracic cage on right side.

Deformities of the forearm and wrist-One or other of the characteristic forearm deformities occurred in almost half of the patients examined, though the more marked manifestations such as radio-humeral dislocation were comparatively uncommon. Figure 3 shows the radiographs of one such patient. The radius is bowed throughout its length, not merely at the distal end where exostoses are common. Moreover, the left radius is bowed though this bone has no exostosis at all.

The gravest effect here is obviously the gross shortening of the ulna. Even when both bones are equally affected by exostoses the ulna is almost invariably more severely shortened than the radius. This growth deficiency is confined to the distal end of the bone, which is typically carrot-shaped; the radio-ulnar joint is often disrupted and the wrist deviated to the ulnar side.

There are at least two reasons for this disproportionate shortening of the distal end of the ulna. Exostoses are rare at the proximal end of either the radius or the ulna, whereas the distal ends are affected in 85 and 68 per cent of cases respectively. This is in keeping with the general observation that the bone ends which contribute most to the total diaphysial 
BONE GROWTH IN DIAPHYSIAL ACLASIS

TABLE I

incidence of Deformities in Seventy-six Patients with Diaphysial Aclasis

\begin{tabular}{|ccccc|}
\hline Sex & $\begin{array}{c}\text { Multiple } \\
\text { exostoses }\end{array}$ & $\begin{array}{c}\text { Associated } \\
\text { deformities }\end{array}$ & $\begin{array}{c}\text { Percentage with } \\
\text { deformities }\end{array}$ \\
\hline Males $\cdot$ & $\cdot$ & 36 & 26 & 72 \\
Females & $\cdot$ & 40 & 30 & 75 \\
\hline Total & $\cdot$ & 76 & 56 & $73 \cdot 7$ \\
\hline
\end{tabular}

TABLE II

The Deformities Present in Seventy-six Patients with Diaphysial Aclasis

\begin{tabular}{|c|c|c|c|c|c|}
\hline \multirow{2}{*}{ Deformity } & \multicolumn{4}{|c|}{ Number of patients } & \multirow{2}{*}{ Percentage } \\
\hline & Both sides & Right side & Left side & Total & \\
\hline All forearm deformities & 15 & 8 & 14 & 37 & 50 \\
\hline Bowed radius. & 13 & 7 & 13 & 33 & 43 \\
\hline Conical ulna & 5 & 6 & 8 & 19 & 25 \\
\hline Radio-humeral dislocation & 1 & 2 & 3 & 6 & 8 \\
\hline Genu valgum . & 7 & 3 & 6 & 16 & 21 \\
\hline Valgus ankles. & 29 & 4 & 1 & 34 & 45 \\
\hline Deformities of the hands. & 6 & 3 & 4 & 13 & 17 \\
\hline Short stature & - & - & - & 31 & 41 \\
\hline Scoliosis & - & - & - & 3 & 4 \\
\hline Pelvic deformities & - & - & - & 3 & 4 \\
\hline Thoracic deformities & - & - & - & 2 & 3 \\
\hline
\end{tabular}

TABLE III

The Relationship between Rate of Growth and Frequency of Exostoses (SEVENTY-SIX CASES)

\begin{tabular}{|c|c|c|c|c|}
\hline Bone & $\begin{array}{l}\text { Proportionate contr } \\
\text { bone length (expre } \\
\text { percentage of total }\end{array}$ & $\begin{array}{l}\text { bution to } \\
\text { sed as a } \\
\text { ongation) }\end{array}$ & $\begin{array}{l}\text { Number of } \\
\text { cases } \\
\text { affected }\end{array}$ & $\begin{array}{l}\text { Percentage } \\
\text { of total }\end{array}$ \\
\hline \multirow{2}{*}{ Femur } & Proximal end & 20 & 58 & 77 \\
\hline & Distal end & 80 & 71 & 94 \\
\hline \multirow{2}{*}{ Tibia } & Proximal end & 60 & 72 & 95 \\
\hline & Distal end & 40 & 62 & 82 \\
\hline \multirow{2}{*}{ Fibula } & Proximal end & 55 & 69 & 91 \\
\hline & Distal end & 45 & 55 & 72 \\
\hline \multirow{2}{*}{ Humerus } & Proximal end & 80 & 65 & 85 \\
\hline & Distal end & 20 & 3 & 4 \\
\hline \multirow{2}{*}{ Radius } & Proximal end & 25 & 10 & 13 \\
\hline & Distal end & 75 & 64 & 85 \\
\hline \multirow{2}{*}{ UIna } & Proximal end & 15 & 7 & 9 \\
\hline & Distal end & 85 & 52 & 68 \\
\hline
\end{tabular}

The figures for the proportionate contribution of the proximal and distal ends to bone length are after Lacroix (1951).

VOL. 43 B, NO. 4 , NOVEMBER 1961 
length are the more frequently affected in diaphysial aclasis (Table III). Although it is almost impossible to determine the exact proportionate contribution of proximal and distal ends to total bone length (indeed, it varies quite widely from person to person), it seems certain that

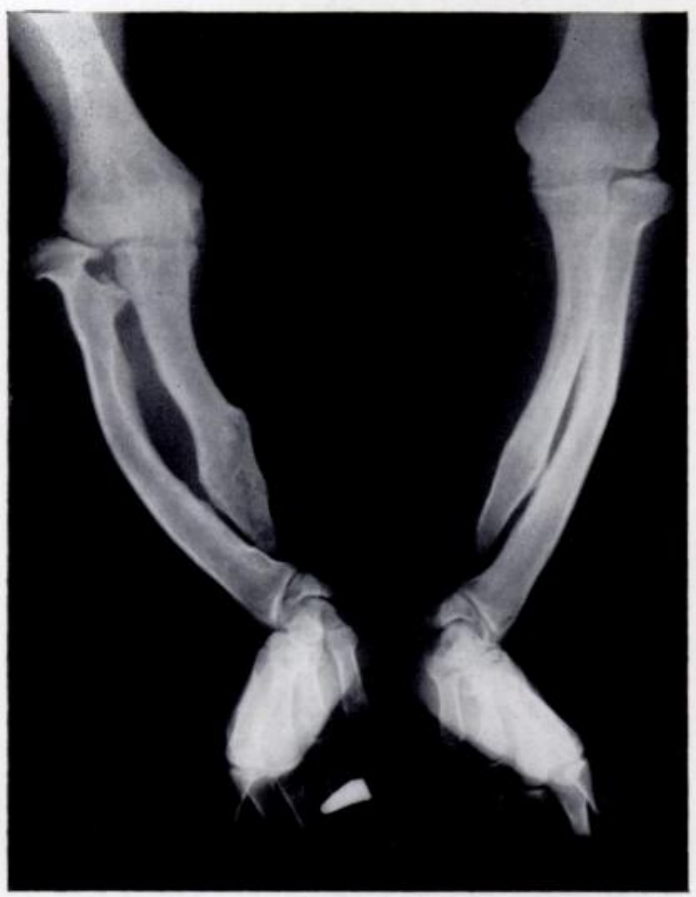

FIG. 3

Radiograph showing the characteristic forearm deformities. The ulna is short and the distal end tapered; the radius is bowed throughout its length and there is subluxation of the right radio-humeral joint. the distal end of the ulna contributes more to total bone length than the distal end of the radius. Equal involvement of these two bones at more or less the same age can therefore be expected to cause a greater diminution in the ultimate length of the ulna than of the radius.

The second possible reason for this undue shortening of the ulna is the difference in cross-sectional area of the epiphysial plates of the two bones, the ulnar plate being less than a quarter the area of the radial plate. " Equal" involvement by exostoses, therefore, means greater proportionate involvement of the ulnar growth plate. Whatever the ultimate mechanism may be, there is evidence that the retardation of growth is related to the extent to which the particular epiphysial plate is disturbed by the disease.

The result of this disproportionate ulnar shortening is that the radius, tethered firmly to the ulna and growing considerably more than the latter, is accommodated in one of two ways: either it bends or there is dislocation of the radio-humeral joint. When dislocation occurs the bowing is less than would otherwise be expected (Fig. 4).

Valgus deformity of the ankle and knee-Obliquity of the tibial articular surface with valgus tilting of the talus occurred in thirty-four of the seventy-six patients, and of these all but five were bilateral and symmetrical (Fig. 5). It is important to notice that the lower epiphysial plate of the tibia remains horizontal; it is not distorted except in the most severe cases, and even then the horizontal disposition is retained though the lateral part of the articular surface is forced right into the metaphysis.

The valgus deformity is almost entirely a deformity of the tibial epiphysis, which is wedgeshaped in all these cases. The underlying reason for this is much the same as with the forearm deformity, namely, a disproportionate degree of shortening of the fibula, and the possible causes of this shortening are the same as those already discussed. The lateral malleolus comes to lie at the same level as-and sometimes higher than-the medial malleolus, though still retaining its strong attachment to the tarsus through the ligaments of the ankle joint. The talus is thus tilted into valgus and drawn up hard against the lateral part of the tibial articular surface, which increasingly bears the stress due to the disproportionate tibial growth. Growth of the tibial epiphysis, which is derived almost entirely from the articular cartilage, is thus interfered with mainly in its lateral half, with consequent wedging of the epiphysis. If the deformity were due to unequal growth at the tibial epiphysial plate, this plate would itself be tilted and distorted obliquely, and this has been shown not to occur.

The same argument applied to the upper end of the fibula and the knee accounts for the valgus deformity of the knee in at least a certain proportion of patients. In others the tibia, attempting to accommodate itself to the shortened fibula, may actually bend in much the same 


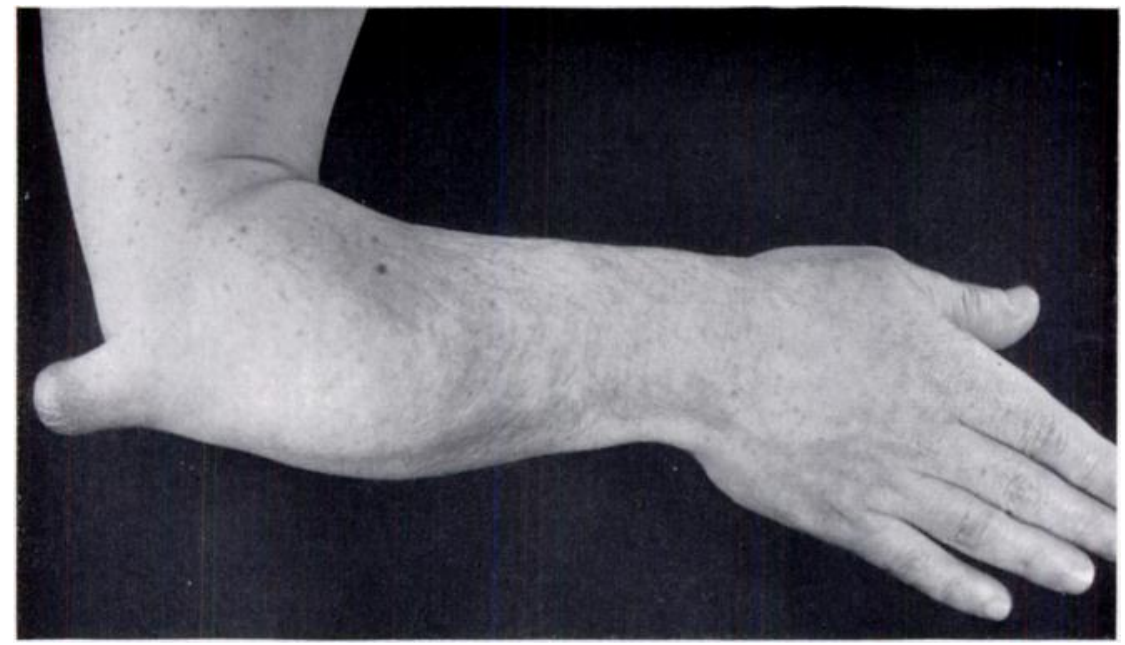

FiG. 4

Dislocation of the radio-humeral joint. The projection at the elbow is not an exostosis: it is due to the proximal end of the radius which has been dislocated since childhood.
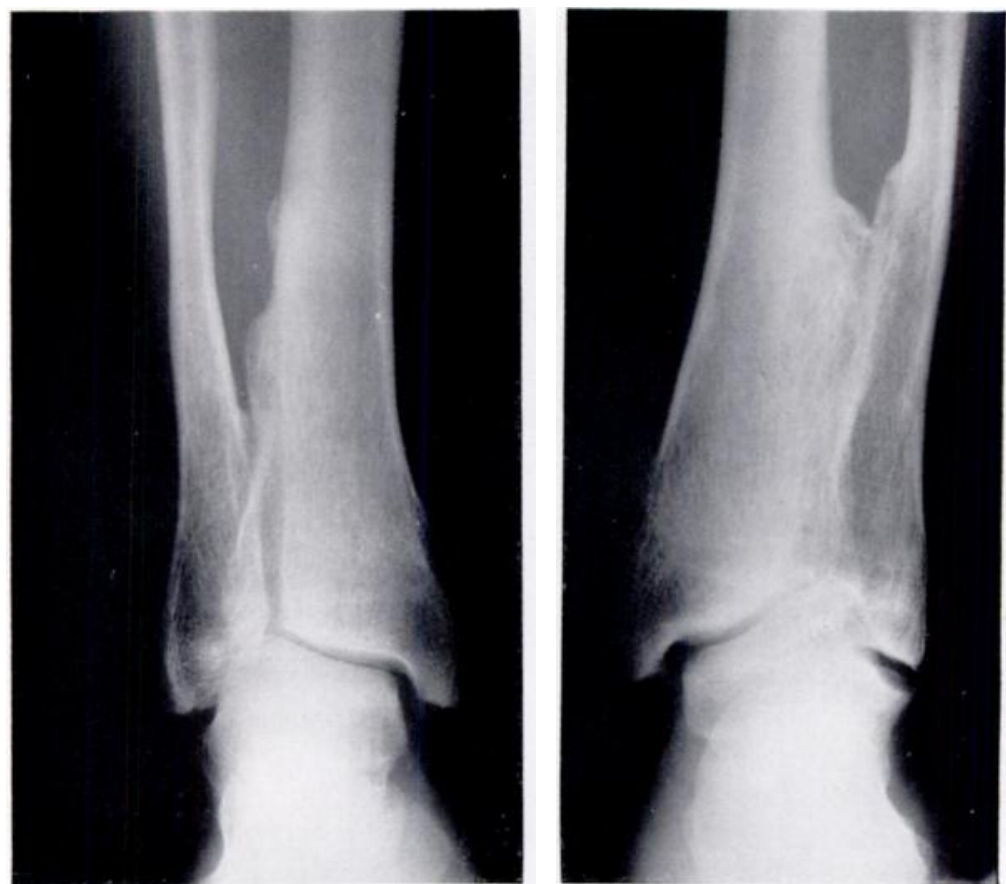

FIG. 5

Radiographs showing valgus deformities of the ankles. Note that in spite of the marked tilting of the tibial articular surface the line of the epiphysial plate is horizontal. 
way as the radius becomes bowed (Fig. 6). Thus, whatever the particular form of the resulting deformity, the inescapable conclusion is that it results from diminished bone length. the "short bone" in this instance being the fibula.

Shortening of the clavicle-Like other bones affected by multiple exostoses, the clavicle may

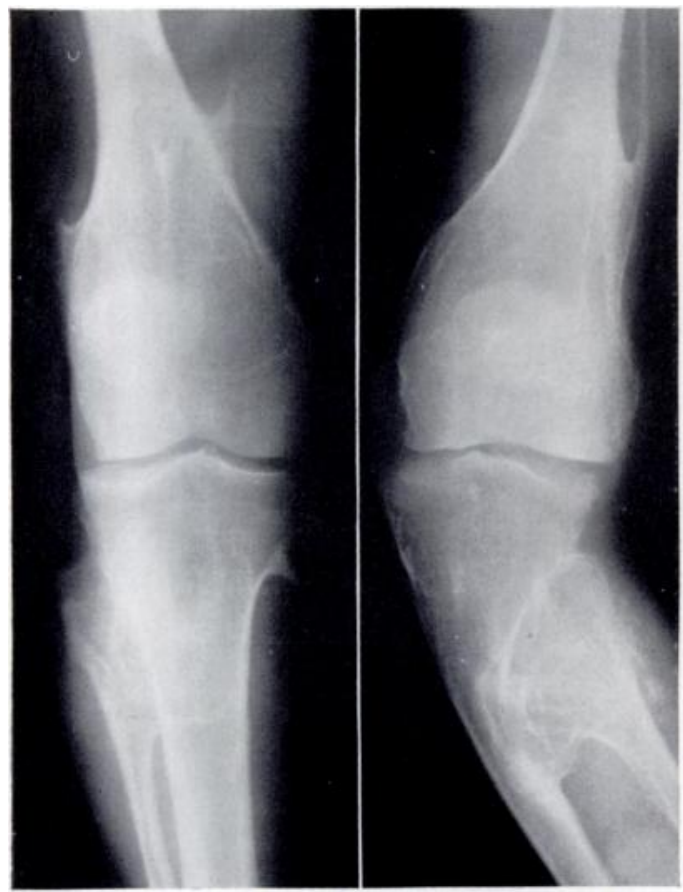

Fig. 6

Radiograph showing genu valgum from bowing of the tibiae. There is also a tibio-fibular synostosis on the left side. be shorter than usual (Fig. 1). It remains only to comment on the fact that this bone should be affected at all. Regarded by many as a membrane bone, it was at one time thought not to be involved in diaphysial aclasis-a disease of the bones preformed in cartilage. Routine radiographs, however, show that the clavicle is involved in 24 per cent of patients with this disease, usually at its acromial end, but sometimes also at its sternal end.

The development of the clavicle has been studied in detail (Fawcett 1913. Hanson 1920, Todd and D'Errico 1928. Gray's Anatomy 1958), and it is not surprising to learn that although the bone is developed directly from the primitive mesenchyme, precartilaginous (and later cartilaginous) elements develop at the sternal and acromial ends shortly before these regions become ossified. There is therefore no reason why the clavicle should not be involved like any other bone that develops through a cartilaginous phase.

Short stature-Some of the earliest descriptions of multiple exostoses comment on the fact that these patients tend to be shorter than normal. This is a general impression which has not been substantiated by detailed anthropometric studies in large series.

The present group of patients were measured for total height, span, symphysial height and length of individual long bones.

The height distribution of these patients is shown in Figures 7 and 8. The standards used were derived from two sources. Up to the age of eighteen Tanner's standards are the most reliable, and a corresponding series of " healthy " children and adolescents attending the hospital as out-patients were found to be evenly distributed along these curves. For the adults Kemsley's standards have been chosen as the most reliable and representative of the studies on British people. It is likely that the present population is slightly taller than is reflected in these standards, obtained before 1943. A series of "healthy" out-patients corresponding in age and sex to the patients with diaphysial aclasis was also measured, and compared with Kemsley's standards they all tend to be slightly taller. The fiftieth percentile in this group falls almost exactly on the seventy-fifth percentile of Kemsley's series. The values shown in Figures 7 and 8 are therefore, if anything, even lower than they seem compared to the normal.

There are several points worthy of comment in these figures. 1) The diminution in height, though undoubtedly evident, is not on the whole great. Only seven patients fell below the third percentile and can be regarded as highly abnormal. 2) The shortness of stature becomes more evident as the end of the growth period is reached. Thus, before puberty there is hardly any deviation from the normal, but from then onwards growth is clearly retarded by comparison 


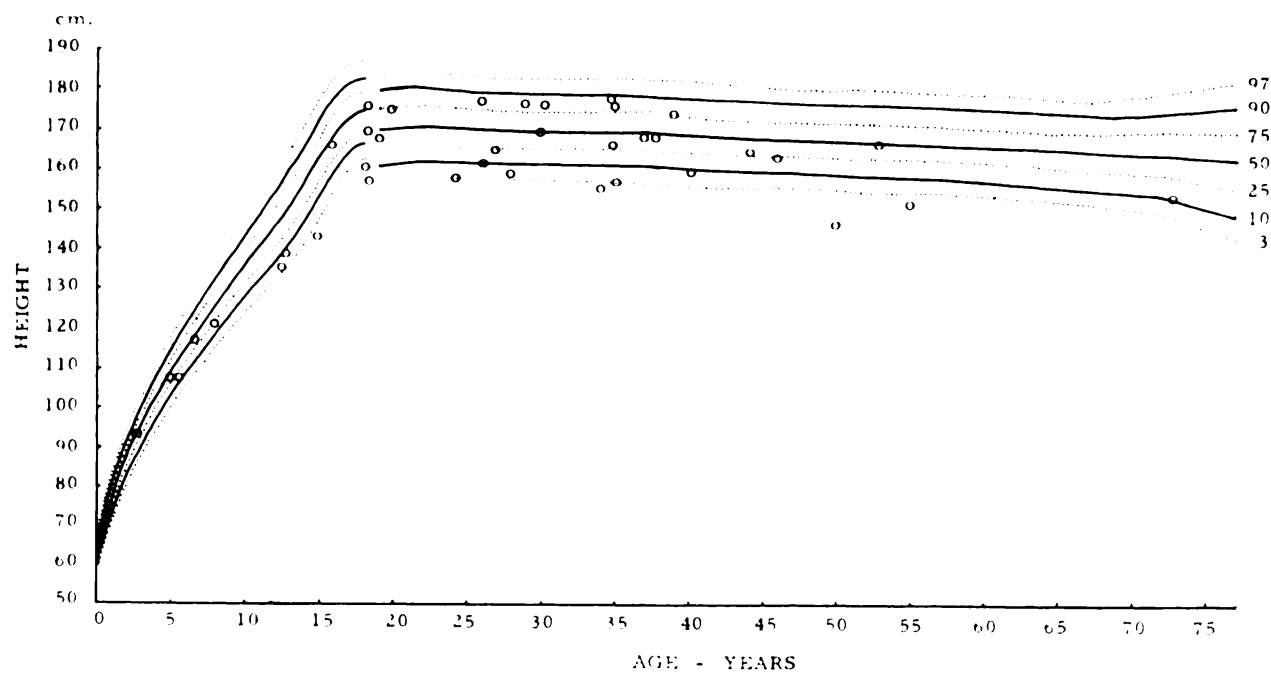

FIG. 7

Analysis of the height distribution in patients with diaphysial aclasis (males). The standard curves are derived from Tanner (1958) and Kemsley (1950), the figures on the right showing the third, tenth, twenty-fifth, fiftieth, seventy-fifth, ninetieth and ninety-seventh percentiles.

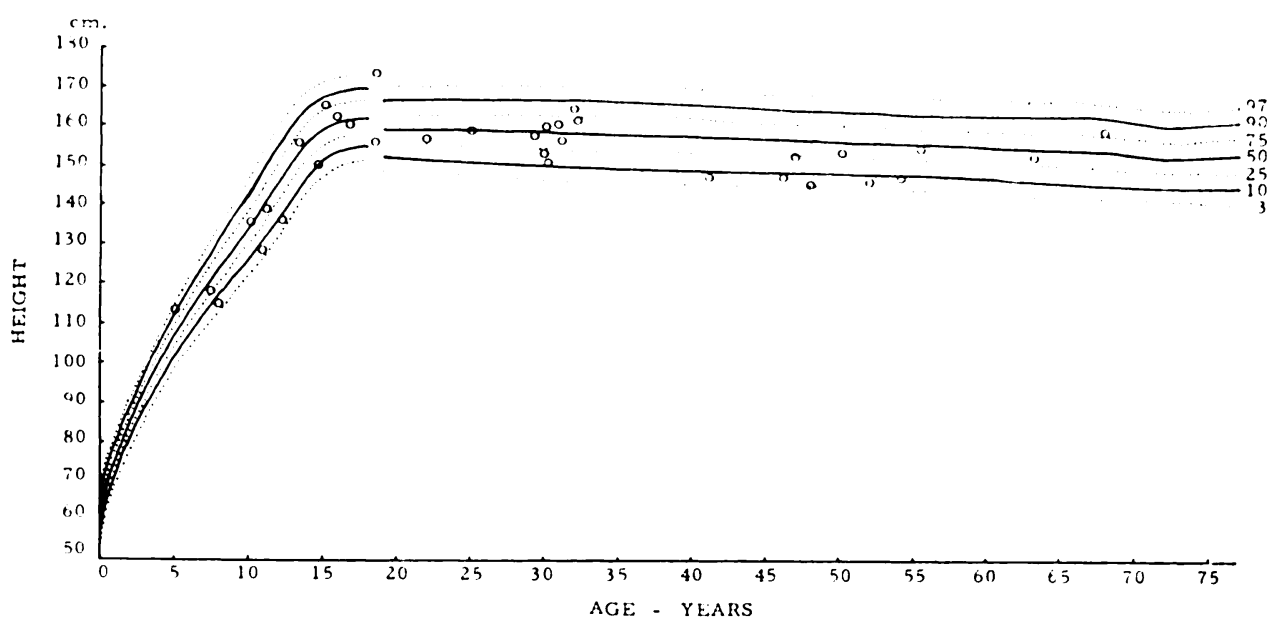

FIG. 8

The height distribution in patients with diaphysial aclasis (females). The standard curves are derived from Tanner (1958) and Kemsley (1950), the figures on the right showing the third, tenth, twenty-fifth, fiftieth, seventy-fifth, ninetieth and ninety-seventh percentiles.

with the normal. 3) Males, on the whole, are more severely retarded than females. This could be explained by the fact that girls reach the end of the growth period earlier than boys and the effects of diaphysial aclasis on growth continue for a considerably longer period in the latter.

As might be expected, this diminution in stature is almost entirely due to shortness of the lower limbs, the trunk being more or less normal. Figures 9 and 10 show the upper and lower measurements in these cases compared with Engelbach's standards (1932). Here again the possible errors were minimised by measuring "healthy" out-patients and the mean values were found to correspond closely to Engelbach's figures, obtained before 1932 mainly on native Americans. The symphysial height is a reliable index of total lower-limb length.

The span, from finger tip to finger tip, measures not only the combined length of the long bones but also that of the hands and the pectoral girdle. These measurements are shown

VOL. 43 B, NO. 4 , NOVEMBER 1961 
in Figures 11 and 12, the standards again being those of Engelbach. Retardation of growth of the tubular bones is reflected to a much greater extent here than in either the symphysial height or the total height.

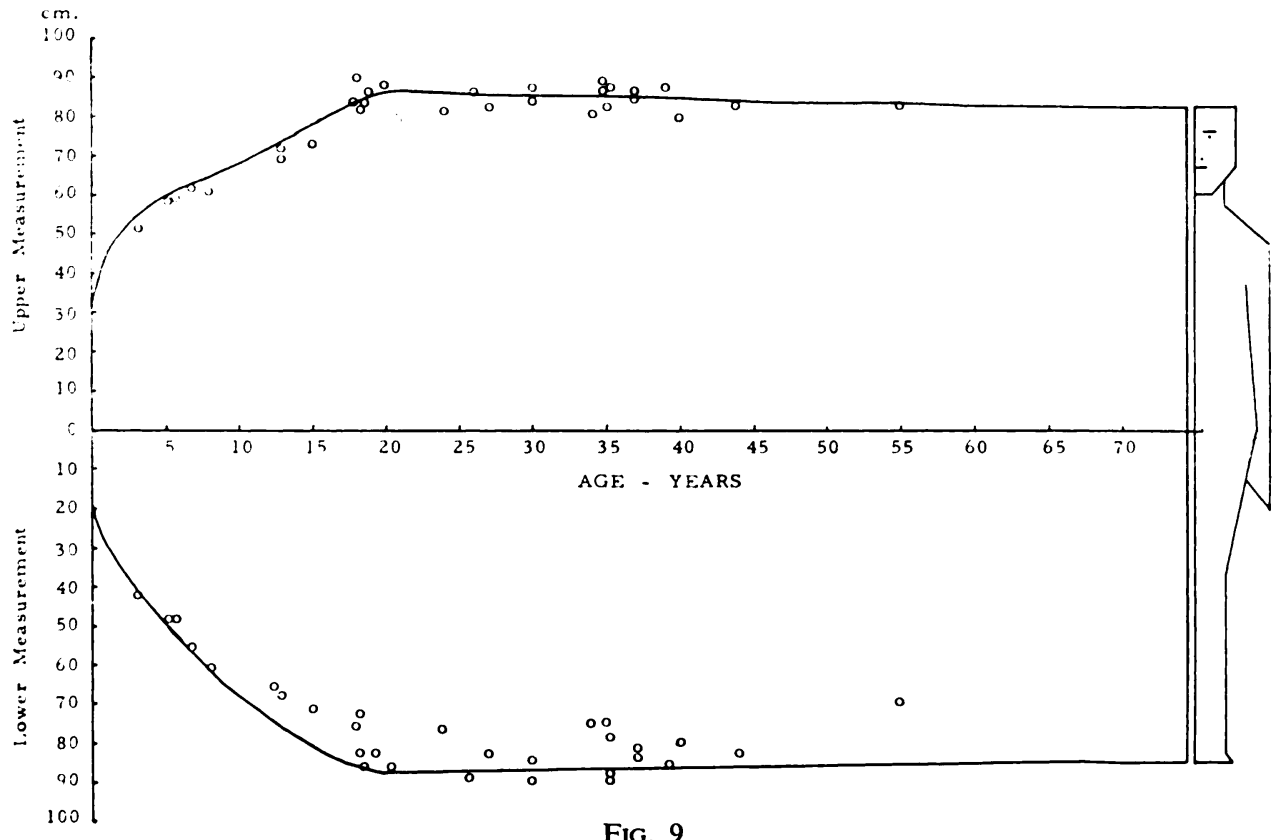

Fig. 9

A comparison of the upper and lower measurements (males). The standards are derived from Engelbach (1932).

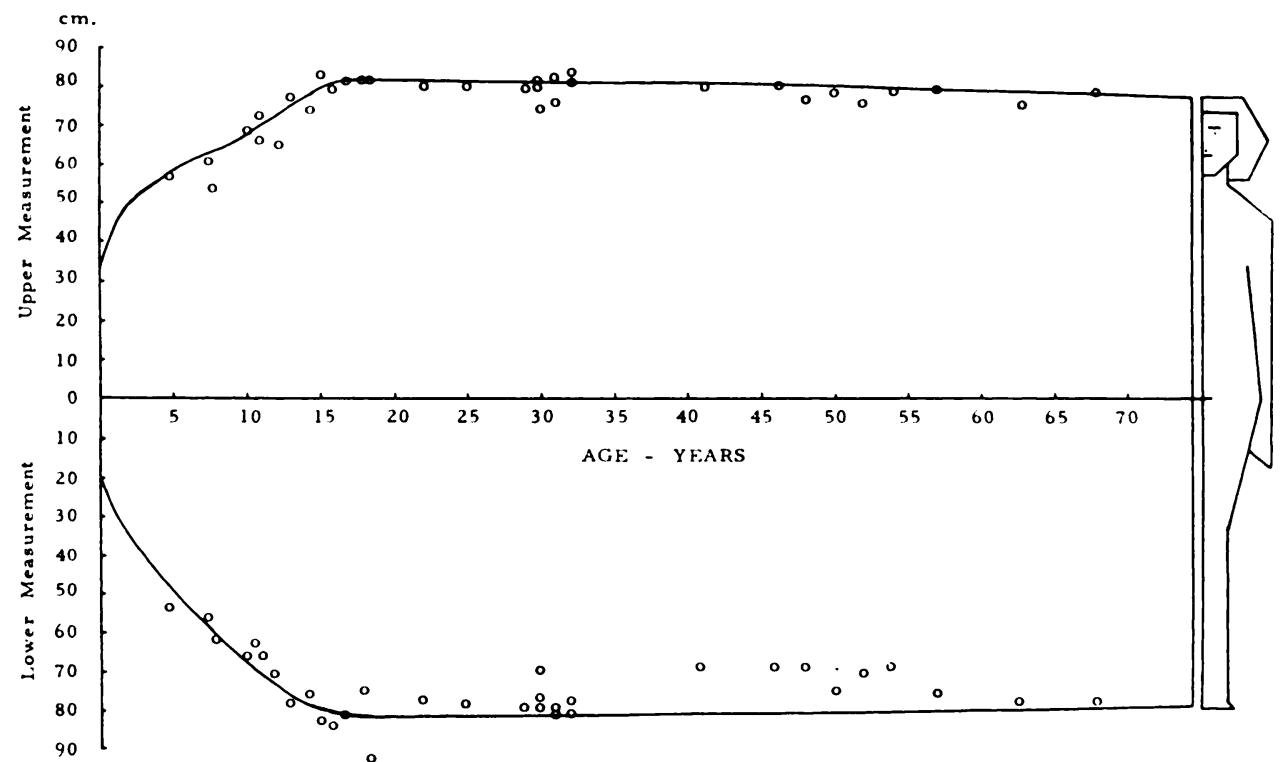

Fig. 10

A comparison of the upper and lower measurements (females). The standards are derived from Engelbach (1932).

There are no reliable clinical standards for comparing the length of the individual bones, but an interesting impression was gained from studying these measurements. The degree of shortening in the long bones tends to be progressively more and more severe in the following order: the femur least of all, then tibia, humerus, radius, fibula and the ulna most severely 
of all. This is exactly in keeping with the suggestion made previously that the degree of shortening is related to the cross-sectional area of the epiphysial plates of the bones affected, the narrowest bones being shortened the most and the widest the least.

Pathogenesis-The future pattern of growth in these cases is quite unpredictable when exostoses first appear. Figures 13 and 14 show the progress of the disease in one child over a period of

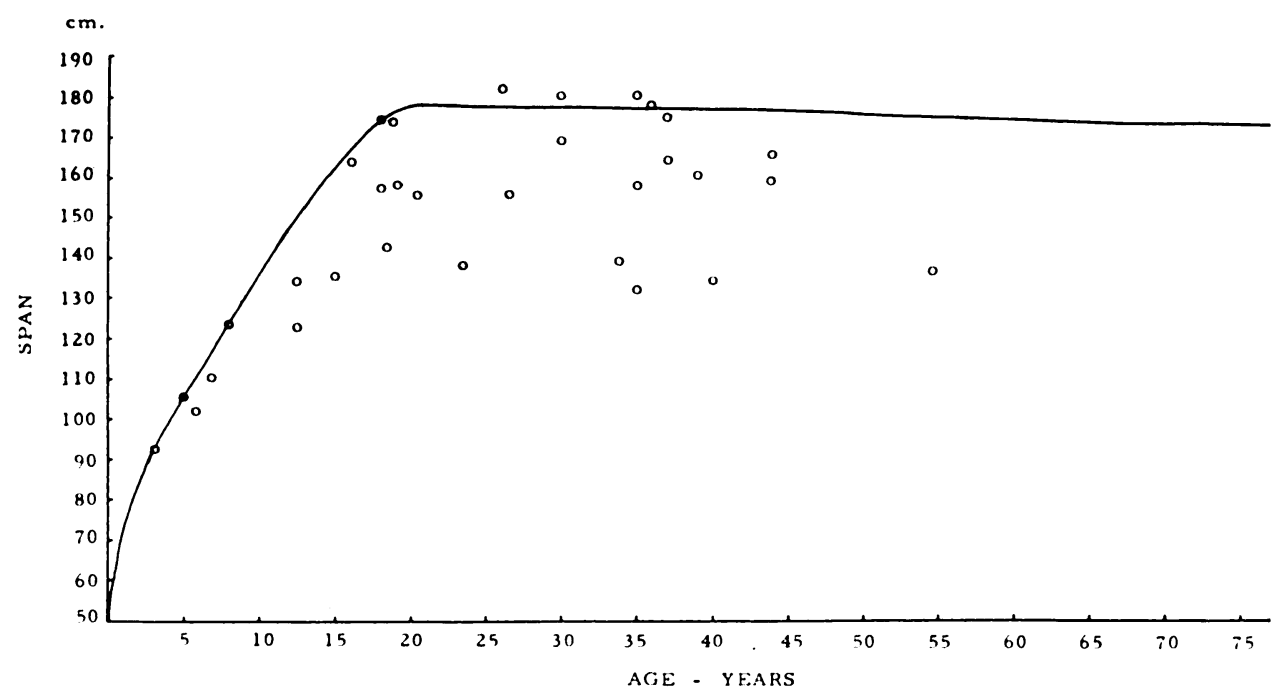

Fig. 11

The measurement of span in diaphysial aclasis (males). The standards are derived from Engelbach (1932).

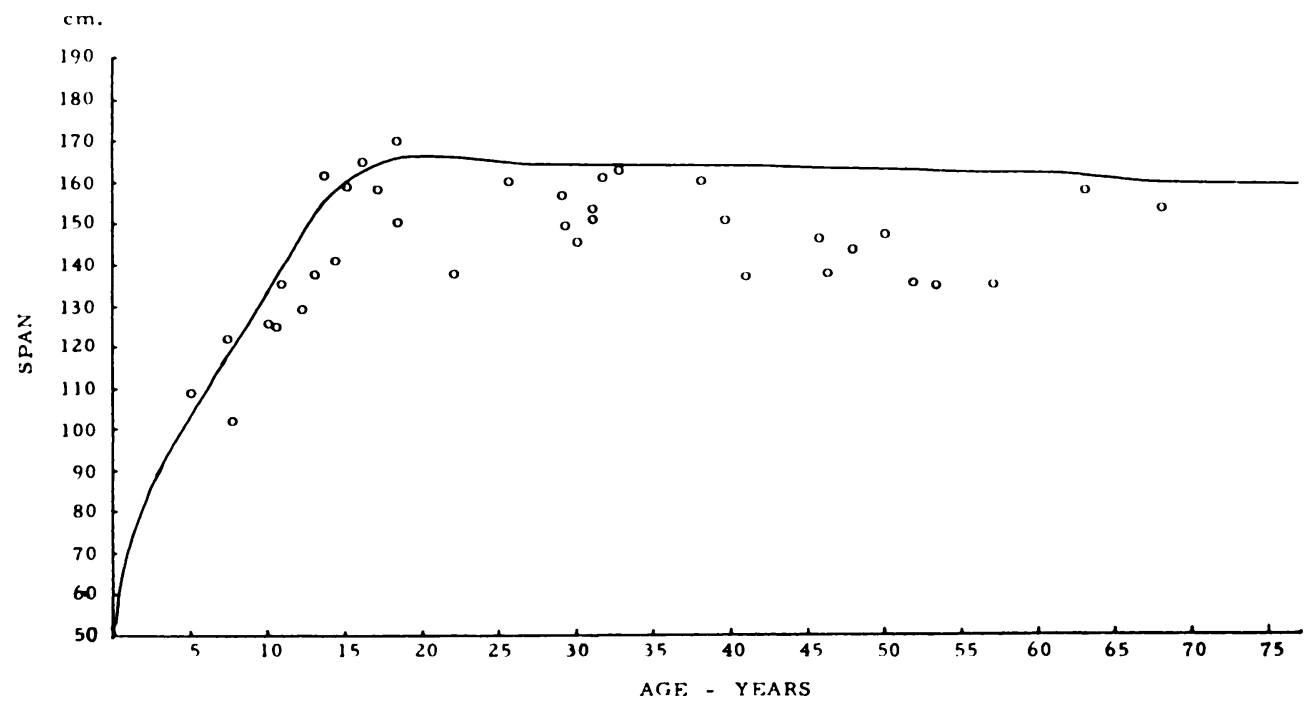

Fig. 12

The measurement of span in diaphysial aclasis (females). The standards are derived from Engelbach (1932).

ten years from the age of three to thirteen. The earliest exostosis at the proximal end of the humerus appeared during the same year as the exostosis at the distal end of the radius. During the next ten years of growth the proximal end of the humerus has continued to grow in its new, grossly abnormal mould with considerable shortening, while over the same period all further growth of the distal end of the radius has been absolutely normal and at the age of thirteen the original exostosis is hardly recognisable half way along the shaft of the bone.

VOL. 43 B, NO. 4, NOVEMBER 1961 
The cause of this retardation in the growth of the long bones in diaphysial aclasis cannot be separated from the cause of the disease as a whole. There is no evidence that it is due to precocious skeletal maturation or early closure of the epiphysial plates, though this belief is still quite widely held (Illingworth and Dick 1956). Figure 15 shows that skeletal maturation in these patients is normal and the epiphyses close at the normal times, whether the bones are affected by multiple exostoses or not.

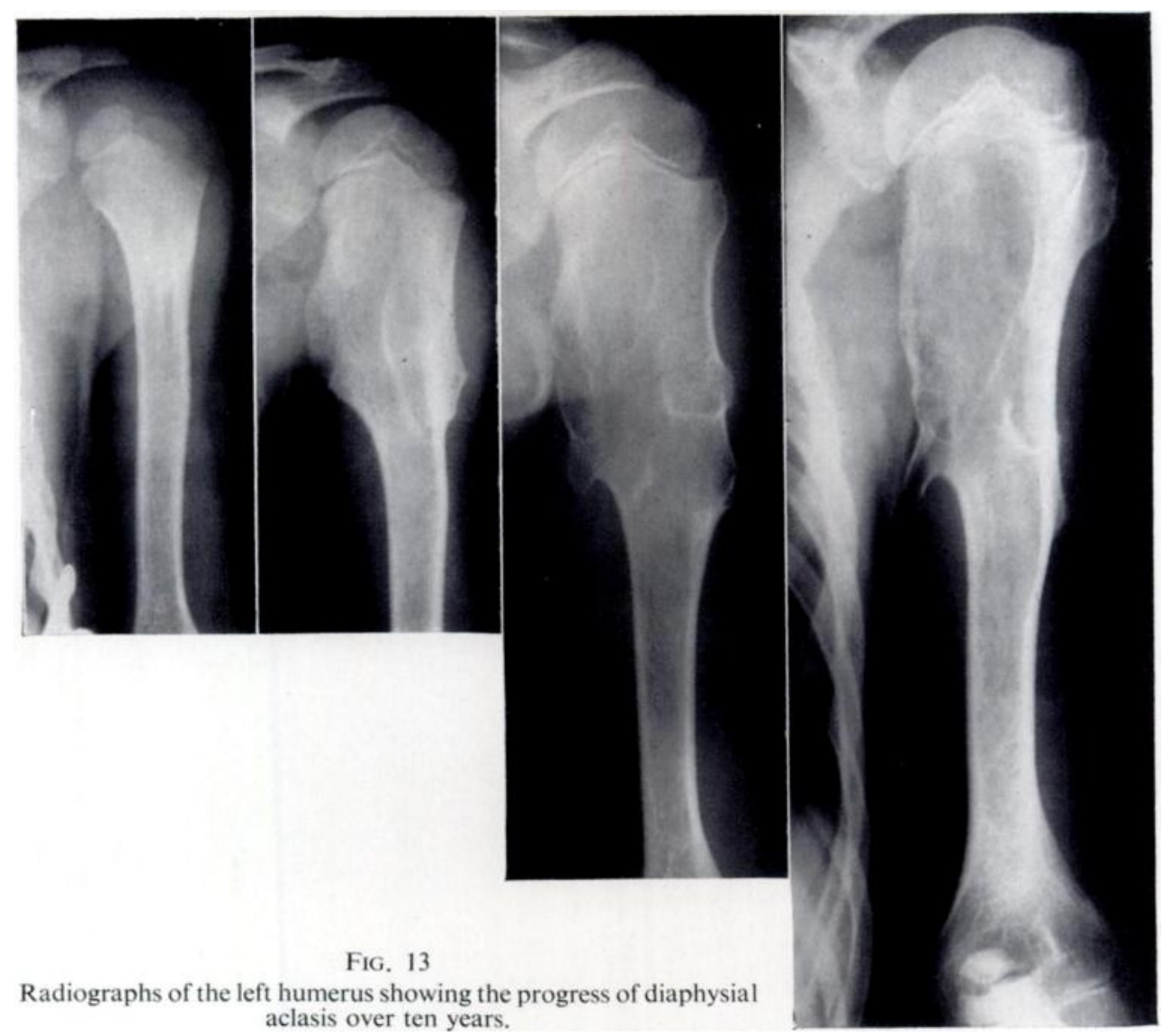

The alternative theory of "squandered growth potential," though couched in less scientific terms, is much more attractive (Jaffe 1943). This theory not only recognises the connection between the occurrence of exostoses and the retardation of growth in the affected bone, but actually regards the one thing as being dependent on the other. The appearance of these abnormal bones suggests that the normal growth potential, which should have been directed to increasing the length of the bone, has been squandered on the formation of abnormally broad metaphyses and multiple exostoses. Certain it is that a bone which is markedly broadened in the metaphysial region, possibly with numerous exostoses as well, is invariably shorter than an unaffected opposite number; but whether the degree of shortening is proportionate to the overall thickening of the metaphysial region is impossible to determine unless the entire skeletal system is available for morbid anatomical studies at various ages during the period of growth.

Apart from emphasising the relationship between the diminution in bone length and broadening of the metaphyses with the formation of multiple exostoses, I have made no attempt here to discuss the etiology of hereditary multiple exostoses, which will form part of a further paper. 
ADAPTATIONS OF BONE GROWTH DUE TO PRESSURE BY ADJACENT EXOSTOSES

Certain abnormalities of bone growth are induced simply by prolonged pressure from adjacent exostoses (Fig. 2). By the process of osteoclastic resorption and bone modelling the growing bone accommodates itself to the obtrusive exostosis in the characteristic way. This occurs quite frequently in the radius and ulna, the tibia and fibula and in adjacent ribs, but may
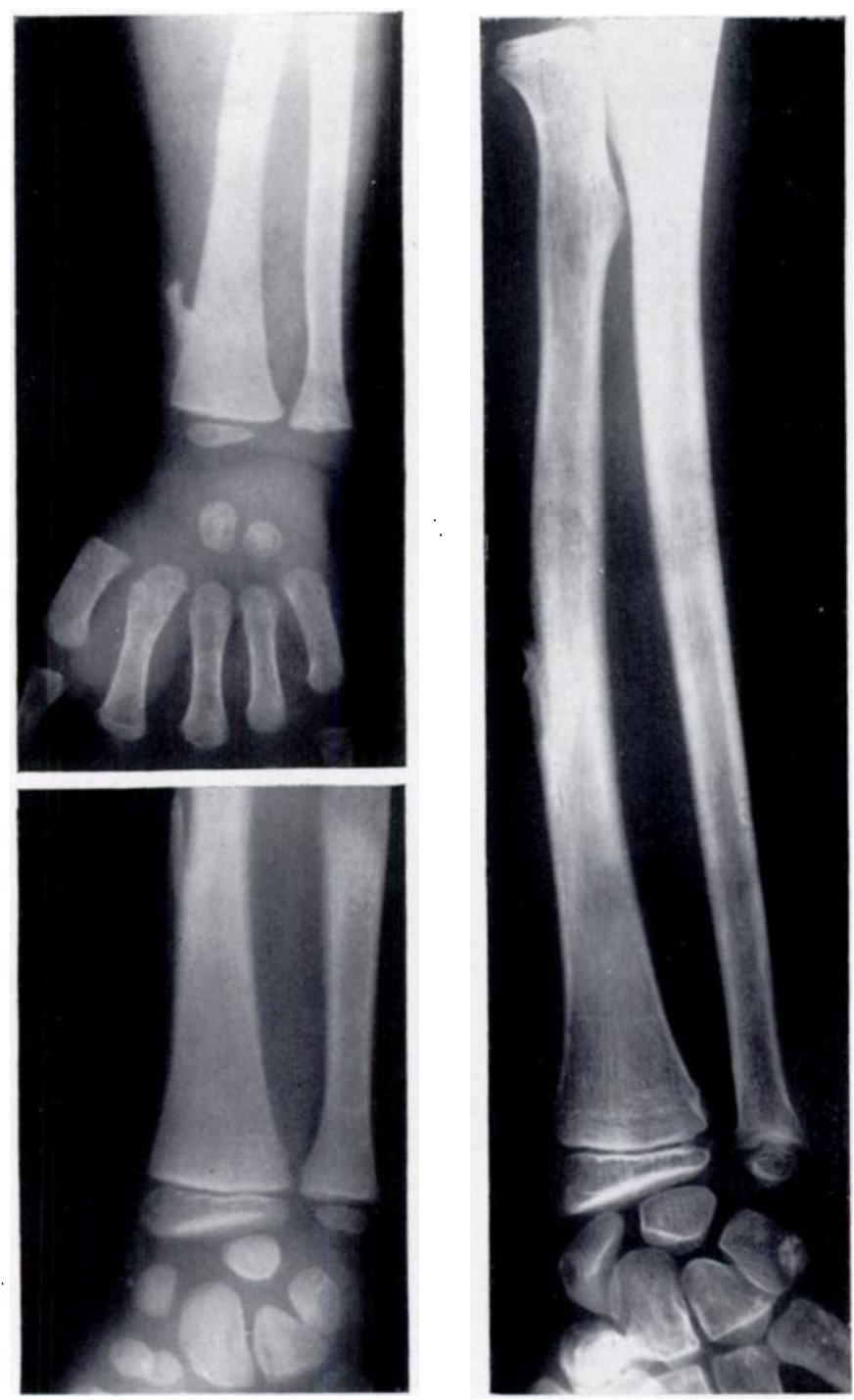

Fig. 14

Radiographs showing the radius and ulna in the same patient as Figure 13.

also be seen in almost any situation where a large exostosis abuts on a neighbouring bone, or even on the very bone from which it arises.

Tibio-fibular synostosis-Whereas a growing bone will mould itself in the manner described, if two adjacent exostoses abut against each other the results are quite different. If either of the two exostoses continues to grow, the one will gradually become embedded in the cartilaginous cap of the other and this may eventually go on to synostosis between the two bones (Fig. 6). This is distinctly unusual in the radius and ulna, where supination and pronation 
movements probably prevent such an outcome, but tibio-fibular synostosis occurred in nineteen (or 25 per cent) of the seventy-six patients in whom complete radiographic examinations were carried out, and of these all but three were affected bilaterally. It is perhaps worth commenting that, apart from the fact that most of these patients also had valgus deformities of the ankles, function was otherwise undisturbed.

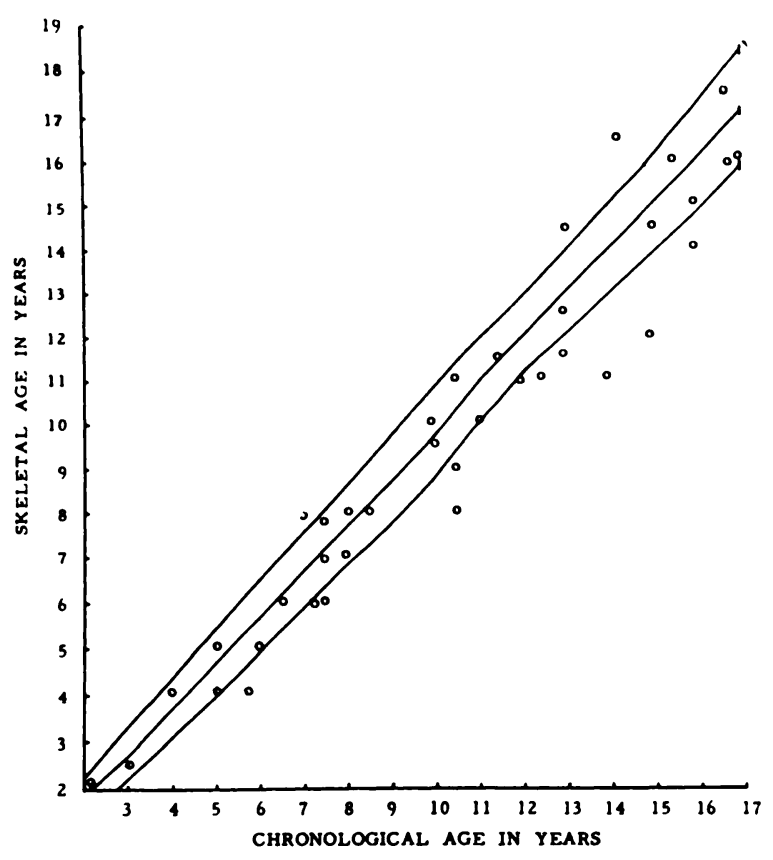

Fig. 15

Skeletal maturation in diaphysial aclasis. The standards are derived from the Harvard series quoted in Greulich and Pyle (1959) and are shown as the mean and one standard deviation above and below.

\section{MIGRATION OF EXOSTOSES}

The exostoses, once formed, may be thought to retain their relationship to each other, at least at their attachment to the diaphysial shaft. In studying the radiographs of children with multiple exostoses one is often struck by the fact that two easily identifiable exostoses-one at the proximal and one at the distal end of the bone-appear to move farther and farther apart over the years. Figure 16 shows two successive radiographs, the one taken at the age of fourteen and the other at the age of sixteen. In the earlier radiograph the exostoses E1 and E2 are 15.1 centimetres apart. In the later radiograph they are 16.8 centimetres apart. Only one other reference to this phenomenon has been discovered in a careful search of the literature (Lacroix 1950). Yet it is the rule rather than the exception for this to occur and it can be demonstrated in almost every case provided appropriate radiographs are taken at successive ages during the period of growth.

The fortuitous co-existence of "Harris's lines" in some of these cases has allowed a comparison with bone growth as a whole. Figure 16 shows that, whereas the distance between the exostoses increases, the distance between the lines $G 1$ and G2 remains the same over the years. In other words, diaphysial length has remained unchanged, while the exostoses have moved farther and farther apart. Logically, there can be only one cause for this phenomenon-namely, progressive osteoclastic resorption on the diaphysial side and simultaneous osteoblastic new bone formation on the epiphysial side of each exostosis. Figures 17 and 18 show the histological features of one such case. This exostosis had 
demonstrably altered its relationship to a nearby Harris's line by no less than 1.5 centimetres over the space of five years. When ultimately excised (on account of continuous pain) a small piece of the adjacent cortex was taken as well (Fig. 17). The base of the exostosis shows numerous osteoclasts in their lacunae along the margin facing towards the mid-shaft, and the bony trabeculae are being actively replaced by rows of osteoblasts massed along the opposite margins.

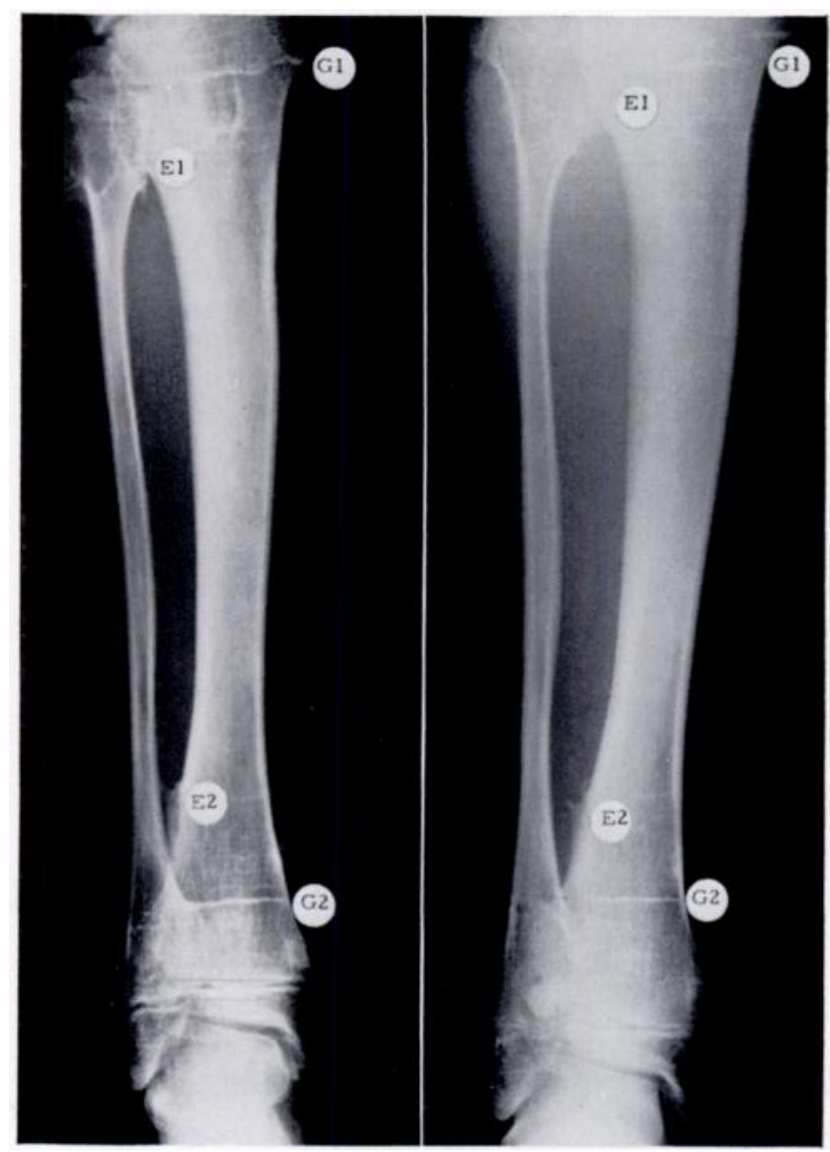

FIG. 16

Radiographs to show the migration of exostoses over a period of two years. The exostoses E1 and E2 have moved farther apart while the lines $G 1$ and $G 2$ have remained unchanged. (Left-hand radiograph aged fourteen years and right-hand radiograph at sixteen years.)

The stimulus for this osteoclastic resorption is possibly, as Lacroix suggests, the differential rate of growth (or "stretching") of the periosteum over the diaphysial cortex as the overall length of the bone increases.

\section{DISAPPEARING EXOSTOSES}

An early reference to disappearing exostoses can be found in John Hunter's Lectures of 1786, published in 1835. Writing about the treatment of the condition he says: "It is hardly ever to be cured by medicines either external or internal, but as it is sometimes spontaneously removed we should endeavour to promote the absorption of it by rousing up this power."

About one-third of the adult patients say that one or more of the bony lumps which they had in childhood have gradually disappeared over the years. This raises an important question and might have a bearing on treatment. These statements were therefore investigated with particular care, and were substantiated in a surprising number of cases.

VOL. 43 B, NO. 4, NOVEMBER 1961 


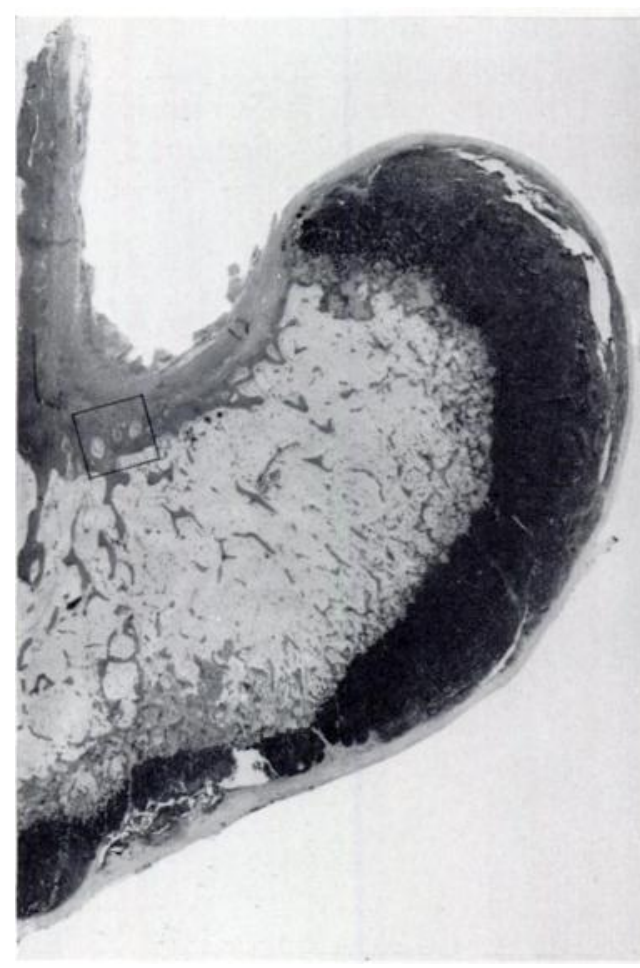

FIG. 17

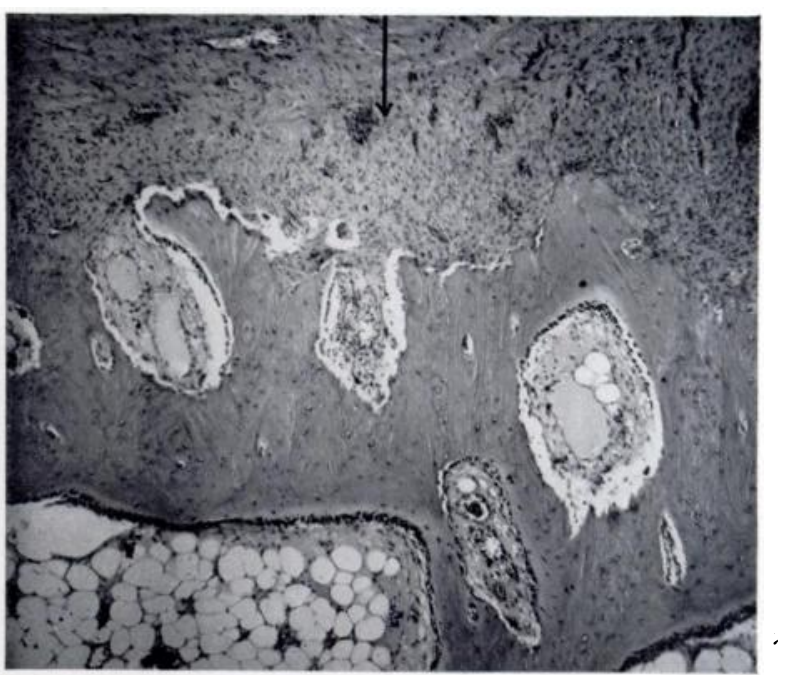

FIG. 18

Figs. 17 AND 18

Figure 17-Photomicrograph of a cartilage-capped exostosis showing the region where osteoclastic resorption and active new bone formation have been demonstrated. Figure 18-Photomicrograph of the area marked out in Figure 17. Osteoblasts are massed along the advancing edges of the bone trabeculae while the trailing edges are ragged with numerous Howship's lacunae. (The arrow shows the direction in which the exostosis is migrating.)

Figure 19 shows a typical example of disappearing exostoses. The exostosis at the base of the proximal phalanx of the left middle finger has disappeared completely by the age of ten: the smaller exostosis which shows at this age at the distal end of the proximal phalanx of the right middle finger has likewise disappeared by the age of thirteen and a half.

The explanation for this is probably quite simple. The overall diameter of the phalangeal shaft plus the exostosis in each case remains unchanged over the years. Clearly the exostosis must have ceased growing while the phalanx enlarged in the normal way, increasing its diameter by appositional growth until the overall dimensions obscured the once prominent exostotic projection.

\section{SUMMARY AND CONCLUSION}

1. The widespread deformities commonly associated with diaphysial aclasis have been studied in seventy-six patients. Apart from the adaptations of growth due to pressure by neighbouring exostoses, all the deformities of the tubular bones can be explained in terms of the same underlying factor-diminished length of the bones affected by the disease.

2. When the condition first manifests itself the future pattern of bone growth is completely unpredictable except in so far as it is known that the more actively growing ends of the long bones are the more severely affected in each case. It has also been shown in this series that, in general, the bones with the smallest cross-sectional area at the epiphysial plates (such as the ulna and the fibula) are the most severely shortened of all.

3. The cause of this disturbance of growth is still unknown, but there is an undoubted relationship between the presence of exostoses or thickening of the metaphysial region and shortening of the bone involved.

4. The phenomena of migrating exostoses and disappearing exostoses are also described and are shown to be examples of the normal process of bone modelling applied in special circumstances. 


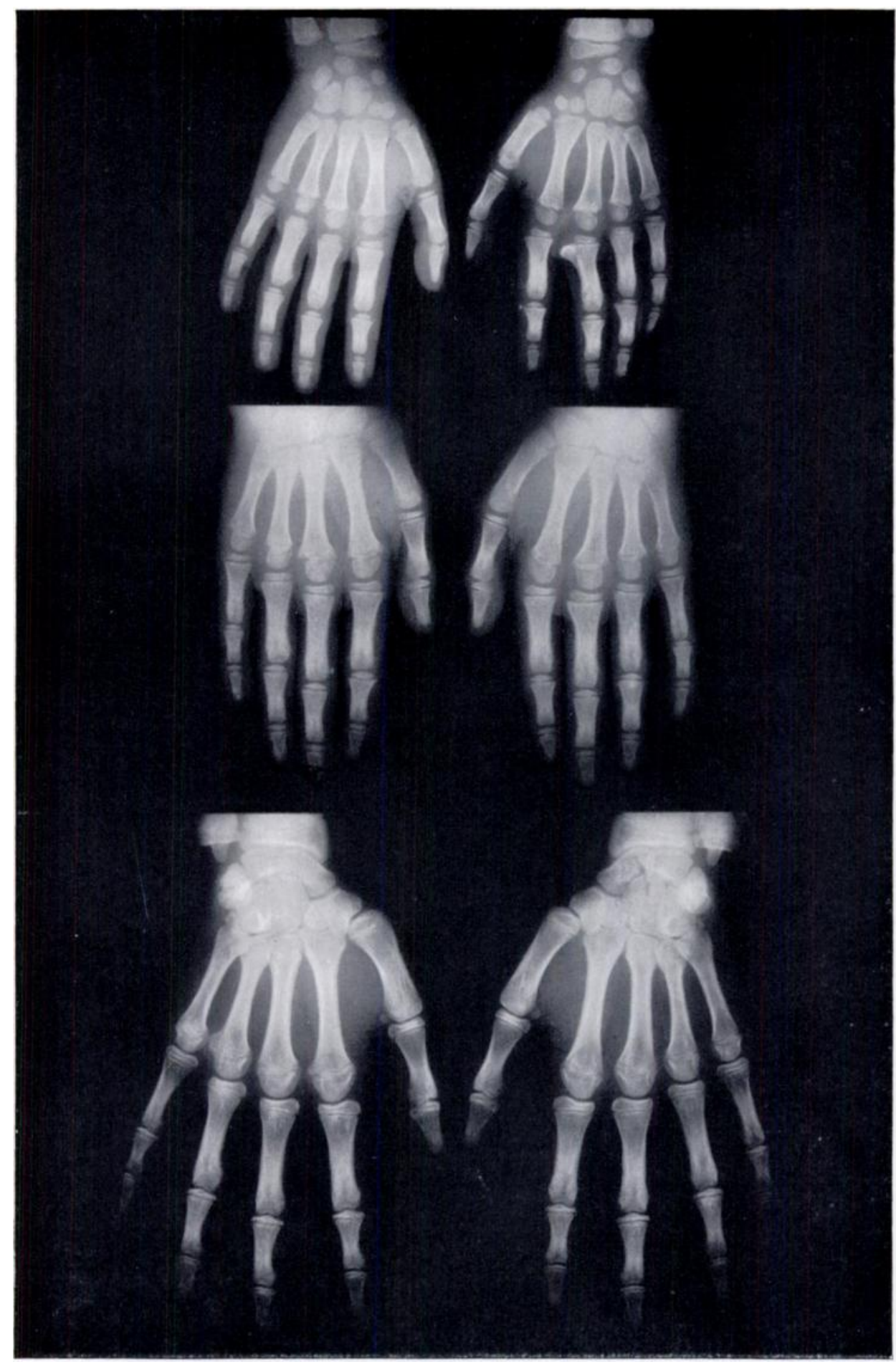

Fig. 19

Successive radiographs of a child's hands showing the disappearance of exostoses between the ages of five years and thirteen and a half years. 
5. Although the importance of the cartilage-capped exostoses is not underestimated, it is hoped that this study will stimulate further work on what is probably the basic defect in this disease-namely, the disturbance of bone growth.

I should like to express my gratitude to Dr H. A. Sissons who first suggested this study and whose interest has been a constant encouragement. I am also grateful to the members of the staffs of the Royal National Orthopaedic Hospital and the Hospital for Sick Children, Great Ormond Street, for allowing me free access to their patients. The photograph for Figure 1 was supplied by the Photographic Department of the Middlesex Hospital. All the other photographs were prepared by Mr R. J. Whitley, Mrs P. Thomas and Mr M. Duffett of the Photographic Department of the Royal National Orthopaedic Hospital.

I should like to thank Miss D. Beridge and Miss D. Hodgkin for their untiring help in arranging the follow-up clinics and preparing the manuscript and tables for this paper.

\section{REFERENCES}

Bessel-Hagen, F. (1891): Ueber Knochen- und Gelenkanomalieen. Archiv für Klinische Chirurgie, 41, 420.

EngelbaCh, W. (1932): Endocrine Medicine. Vol. I. Springfield, Illinois: Charles C. Thomas.

FAwCETT, E. (1913): The Development and Ossification of the Human Clavicle. Journal of Anatomy and Physiology, 47, 225.

Gray's Anatomy (1958): Thirty-second edition. Edited by T. B. Johnston, D. V. Davies and F. Davies. London: Longmans, Green and Co.

Greulich, W. W., and Pyle, S. I. (1959): Radiographic Atlas of Skeletal Development of the Hand and Wrist. Second edition. California: Stanford University Press.

Hanson, F. B. (1920): The History of the Earliest Stages in the Human Clavicle. Anatomical Record, 19, 309.

HUNTER, J. (1835): The Works of John Hunter, F.R.S. With Notes by J. F. Palmer. Vol. I. London: Longman, Rees, Orme, Brown, Green \& Longman.

Illingworth, C. F. W., and Dick, B. M. (1956): A Textbook of Surgical Pathology. Seventh edition. London: J. \& A. Churchill Ltd.

Jaffe, H. L. (1943): Hereditary Multiple Exostosis. Archives of Pathology, 36, 335.

KeIth, A. (1920): Studies on the Anatomical Changes Which Accompany Certain Growth-disorders of the Human Body. Journal of Anatomy, 54, 101.

Kemsley, W. F. F. (1950): Weight and Height of a Population in 1943. Annals of Eugenics, 15, 161.

LACRoIX, P. (1950): Contribution a l'étude de la maladie exostosante. Revue d'Orthopédie, 36, 20.

LACrolx, P. (1951): The Organization of Bones. (English Translation.) London: J. \& A. Churchill, Ltd.

TANNER. J. M. (1958): The Evaluation of Physical Growth and Development. In Modern Trends in Paediatrics. Second Series. Edited by A. Holzel and J. P. M. Tizard. London: Butterworth and Co. (Publishers) Ltd.

TodD, T. W., and D'Errico, J., Jun. (1928): The Clavicular Epiphyses. American Journal of Anatomy, 41, 25. VIRCHOW, R. (1876): Ueber die Entstehung des Enchondroms und seine Beziehungen zur Enchondrosis und Exostosis cartilaginea. Monatsberichte der Königlichen Preussischen Akademie der Wissenschaften, p. 760. 